\title{
Unintended consequences of cigarette price changes for alcohol drinking behaviors across age groups: evidence from pooled cross sections
}

\author{
Deborah L McLellan ${ }^{1 *}$, Dominic Hodgkin ${ }^{1}$, Pebbles Fagan ${ }^{2}$, Sharon Reif ${ }^{1}$ and Constance M Horgan ${ }^{1}$
}

\begin{abstract}
Background: Raising prices through taxation on tobacco and alcohol products is a common strategy to raise revenues and reduce consumption. However, taxation policies are product specific, focusing either on alcohol or tobacco products. Several studies document interactions between the price of cigarettes and general alcohol use and it is important to know whether increased cigarette prices are associated with varying alcohol drinking patterns among different population groups. To inform policymaking, this study investigates the association of state cigarette prices with smoking, and current, binge, and heavy drinking by age group.

Methods: The 2001-2006 Behavioral Risk Factor Surveillance System surveys $(n=1,323,758)$ were pooled and analyzed using multiple regression equations to estimate changes in smoking and drinking pattern response to an increase in cigarette price, among adults aged 18 and older. For each outcome, a multiple linear probability model was estimated which incorporated terms interacting state cigarette price with age group. State and year fixed effects were included to control for potential unobserved state-level characteristics that might influence smoking and drinking.
\end{abstract}

Results: Increases in state cigarette prices were associated with increases in current drinking among persons aged 65 and older, and binge and heavy drinking among persons aged 21-29. Reductions in smoking were found among persons aged 30-64, drinking among those aged 18-20, and binge drinking among those aged 65 and older.

Conclusions: Increases in state cigarette prices may increase or decrease smoking and harmful drinking behaviors differentially by age. Adults aged 21-29 and 65 and older are more prone to increased drinking as a result of increased cigarette prices. Researchers, practitioners, advocates, and policymakers should work together to understand and prepare for these unintended consequences of tobacco taxation policy.

Keywords: Cigarette price, Tobacco policy, Smoking, Drinking behaviors, Age, Young adults, Older adults

\section{Background}

Alcohol and tobacco use lead to enormous human and economic costs in the U.S. In the past few decades overall rates of smoking and drinking have declined [1,2]. However, alcohol contributes to about 98,000 deaths annually [3], and smoking, 443,000 deaths [4]. Annual direct and indirect alcohol-related costs approach $\$ 185$ billion, while nearly $\$ 158$ billion in health-related costs are ascribed to

\footnotetext{
* Correspondence: deborah_mclellan@comcast.net

'Institute for Behavioral Health, Heller School for Social Policy and Management, Brandeis University, 415 South Street, MS035, Waltham, MA 02454-9110, USA

Full list of author information is available at the end of the article
}

smoking [5,6]. Raising prices through taxation on tobacco and alcohol products is a common strategy used internationally to raise revenues and reduce consumption, especially among youth [1,2,7-12]. Taxation policies are product specific and focus either on alcohol or tobacco. An emerging body of economic literature, however, documents the interactions between the price of tobacco and use of alcohol [13-18]. These "cross-price" influences reflect a change in the demand for a good (e.g. alcohol) in response to an increase in price of another good (e.g. cigarettes) [19]. It is not known if increased prices on cigarettes are associated with binge or heavy alcohol 
drinking patterns across different age groups. To inform policymaking, it is important to know whether and how strategies to reduce cigarette use, such as cigarette taxation, influence drinking behaviors, and whether these effects differ across age groups.

\section{Underlying mechanisms influencing use and co-use of alcohol and nicotine}

Biological, genetic, behavioral, socio-demographic, and policy factors can provide insight into understanding the link between alcohol and tobacco use and co-use that may, in turn, influence how tobacco control policies influence drinking behavior. Studies suggest there are biological and shared genetic components in using and becoming dependent on alcohol and nicotine both separately and together [20-23]. Behavioral mechanisms also link alcohol and tobacco, such as level of impulsivity, self-medication for psychological issues such as anxiety and depression, and reinforcement effects that help to explain how smoking and drinking can be triggers for each other [24].

Socio-demographic factors such as age, gender, race/ ethnicity, education, socio-economic status, marital status, and employment status are associated with differences in smoking and drinking [25,26]. For example, younger people tend to have higher rates of smoking and binge drinking than those aged 65 and older [25,26], men have higher rates of smoking and drinking than women [25,26], Native Hawaiian/Pacific Islanders report the highest smoking and binge and heavy drinking rates compared to other racial/ethnic groups and Asian Americans report the lowest $[25,26]$. Studies show that full-time college students have the highest rates of binge and heavy drinking and those with college degrees have lower rates of smoking than those with 9-11 years of education [25,26]. Persons who are below the federal poverty level are more likely to smoke and less likely to drink than those who are above the federal poverty level $[25,27]$. Those who are in a partnership, and specifically those who are married, are less likely to have problematic drinking patterns and are less likely to be smokers [28-30]. Persons who are employed or out of the workforce (e.g. homemakers, students, retired individuals) are less likely to smoke than those who are unemployed [31]. The employed have higher rates of current drinking, but lower rates of problematic drinking than those who are unemployed [26].

Socio-economic and governmental practices and policies influence use. As an example, tobacco and alcohol companies use similar advertising and marketing practices which have been found to increase consumption of tobacco and alcohol [32,33]. Governmental policies impacting the pricing, taxation, and sales of tobacco and alcohol products have been shown to influence consumption of both products, individually and together $[34,35]$. Generally, higher prices reduce consumption of each product individually. Policies can also have impacts across products. For instance, tobacco control policies have been found to have effects on drinking behaviors. A study reported that smoking bans in bars are associated with higher traffic fatalities as drunk drivers travel further to bars allowing smoking [36].

Economics provides an understanding of further mechanisms influencing smoking and drinking. According to the theory of consumer demand, an increase in the price of a good (e.g. cigarettes) would be predicted to lower consumption of that good [37]. However, demand theory also recognizes that relationships between the demands for products may exist, so that when prices increase on one product it can have different effects on the use of both products, depending on the relationship. For instance, if two products are close "substitutes," a price increase in one (e.g. cigarettes) will make a consumer buy more of the substitute (e.g. alcohol), and the cross-price relationship will be positive [37]. Alternatively, goods may be "complements," in which case, when the price of cigarettes rises, the demand for both cigarettes and alcohol subsides, revealing a negative crossprice relationship [37].

In policy-making, cross-price relationships of goods may lead to intended and unintended consequences. For instance, increases in the price of cigarettes through taxation may decrease consumption of cigarettes (an intended consequence) and decrease harmful alcohol consumption if the goods are complements, arguably a positive unintended consequence. However, if the goods are substitutes and harmful drinking patterns amplify, then a negative unintended consequence might occur after cigarette prices increase. As policymakers may focus on the reduction of cigarette and alcohol consumption by youth and young adults as a reason for raising excise taxes, whether these taxes are associated with cigarette and alcohol use by young, in comparison with older persons, may be of interest to them.

While some literature examines the influence of cigarette prices on the prevalence and consumption of alcohol, there is no consensus among researchers on whether drinking increases or decreases as a result of cigarette prices $[13,14,16-18,38]$. One study found that higher cigarette prices increase drinking among adults over the age of 18 [13]. Others found a similar response among adults aged 51 and over [38], and among teens [18]. In contrast, some studies found that increasing the price of cigarettes reduces drinking $[14,17,39,40]$. Dee found that teens reduce drinking in response to increases in cigarette price, although in models with added controls, the relationship was no longer statistically significant [14]. A study of those 14 and older in Australia reported reduced drinking in response to increased cigarette prices as did studies in the U.K. and Sweden using sales data $[17,39,40]$.

Only one of these studies investigated the impact of increases in cigarette price on current and binge 
drinking [14]. No studies have examined the influence of increases in cigarette price on different drinking patterns across various age groups. This is a notable gap since drinking and smoking rates vary dramatically by age. For example, the prevalence rates of binge drinking among adults aged $18-20$ are $30-40 \%$, are as high as $50 \%$ among adults aged 21-29, and are 23-30\% among adults aged 30-49 [41]. After age 50 binge drinking drops; $12-19 \%$ of adults aged $50-64$ and $8 \%$ of adults over the age of 65 binge drink [41]. While smoking prevalence rates are $20 \%$ for adults aged 18-64, they drop by half to $9.5 \%$ for persons over age 65 [42].

Given public health goals of preventing and reducing binge and heavy drinking, and the sharp differences in drinking patterns by age, this study aimed to address the significant gap in the literature on the impact of increased state cigarette price on alcohol drinking behaviors across age groups, with a particular focus on younger age groups. Since most of the U.S. research suggests that increases in cigarettes prices are associated with reductions in smoking and increases in drinking among the young, the primary hypothesis of this research was that increases in state cigarette prices would produce stronger reductions in current smoking, and stronger increases in current, binge, and heavy drinking among young adults (those under 30 years of age), than among those aged 30-64 and 65 and older.

\section{Methods}

\section{Data and sample}

This study analyzed six years (2001-2006) of nationally representative data from the Behavioral Risk Factor Surveillance System (BRFSS) surveys. Full details of the BRFSS design are available elsewhere [43]. The price and policy variables described below were merged into the BRFSS yearly data and then data were pooled. The BRFSS data identify the state in which a respondent resides-critical information for this study about impacts of state-level variables.

Due to different stratification sampling approaches, the U.S. territories were dropped from the sample, as were observations from Maine, New Hampshire, and Rhode Island ( $\mathrm{n}=74,581$ ) which did not report results for the beer price variable. This yielded a sample size of 1,623,615 independent observations. Listwise deletion was used to address missing data $(n=299,857)$ [44], leaving a final sample of $1,323,758$ for the analysis of data on current and heavy drinking. For binge drinking, the sample included 1,050,573, observations as we dropped observations from 2006 due to a change in definition of binge drinking for women in that year. The sample included users and non-users of cigarettes and alcohol.

\section{Measures}

Current smoking and current, binge, and heavy drinking

The four dichotomous outcome measures were current smoking; and current, binge, and heavy drinking. Participation in current smoking; and current, binge, and heavy drinking were coded as 1 for survey participants who responded that they participated in these behaviors and coded 0 otherwise. During 2001-2006 the BRFSS defined current smoking as having smoked in the last 30 days, and current drinking as having at least one alcoholic beverage in the past 30 days [45]. For men, heavy drinking was defined in the BRFSS as having on average more than two drinks per day, and for women, more than one per day in the last 30 days. In 2001-2005, binge drinking was defined as having five or more drinks on one occasion in the last 30 days.

\section{Cigarette price}

The main explanatory variable was cigarette price, a continuous variable reflecting weighted average price of cigarettes (including generic brands) in dollars by state and year [46]. To correct for changes in price levels over time due to inflation, we deflated cigarette prices for the years 2001-2006 by the national Consumer Price Index (CPI) in constant 1982-4 dollars, the standard base year of the CPI used in the literature $[47,48]$. Reflecting other literature, the price included the federal tax, but did not include state and local taxes $[46,49]$. This variable was linked to the BRFSS state variable for each respondent.

\section{Age}

The age variable consisted of categories of those aged 18-20, 21-29, 30-64, and 65 years and over, in order to observe hypothesized variation between younger age groups (those under the age of 30) and older age groups. Binge and heavy drinking rates are highest among younger age groups and drop dramatically after age 65; an overall flattening of prevalence rates occurs between ages 30-64. Thus, we focus on differentiating the age groups of those under 30. Also, increases in excise taxes are passed by policy makers to reduce the prevalence of smoking and drinking among young people $[1,10]$.

\section{Other covariates}

Additional individual-level variables were used to adjust for potential influences on smoking and drinking behaviors: gender; race/ethnicity; educational level; and partner, employment, and poverty status. Gender was a dichotomous variable, with males being the reference group. Race/ethnicity was an eight-category variable with Non-Hispanic whites as the reference group. The educational level variable had four categories with college graduates and above as the reference category.

Since drinking and smoking may vary by partner, employment, and poverty status, as described above, we used 
them for adjustment purposes. We collapsed them into categories that would have meaning for both alcohol and tobacco use. Partners (i.e. married or in an unmarried couple) were coded as 1 and those who were not in a partnership (i.e. divorced, widowed, separated, never married) were coded as 0. Employment status included the categories unemployed, employed (reference group), or not in the labor force. Poverty status was a categorical variable that was calculated using U.S. Department of Health and Human Services (DHHS) guidelines which included household income, household size, and state of residence [50]. The BRFSS income variable was an ordinal categorical variable grouped into eight ranges of household income. As the BRFSS categories did not exactly parallel the DHHS poverty guidelines, the "poverty status" variable in this study had three categories of those who were 1) definitely not poor, 2) definitely poor, and 3 ) may be poor. This third category of "may be poor" included those respondents whose category of household income straddled the cutoff points for definitely not poor, or definitely poor. Those with incomes that are definitely above the poverty level (i.e. definitely not poor) were the reference group. Other variables of theoretical interest were not included, either because they were highly collinear with existing variables (e.g. occupation), or were not available in the BRFSS (e.g. addiction level).

\section{State-level policy and economic covariates}

Beer price data from the American Chamber of Commerce Researchers Association (ACCRA) reported the retail price of a six-pack of Heineken and included federal, state, and local taxes, but excluded sales taxes and deposits [51]. ACCRA's decision to use Heineken as the beer brand for beer price may not be reflective of all drinkers' brand choice, since it is a medium-priced beer. Yet, these data are widely used in the literature [52] and are one of the only comprehensive sources of beer price over time. As with the smoking price variable described above, the beer price was in constant 1982-4 dollars $(=1.00)$ adjusted for inflation.

We developed an ordinal variable measuring smoking restrictions (range 0-12) for each state. Drawing on prior work [47,53], the variable was calculated by identifying for each state the strength of smoking restrictions within private worksites, governmental worksites, restaurants, and bars $[47,54,55]$. We rated each venue on the strength of its smoking restriction, coded from 0 (no restrictions) to 3 (smoking is banned). Then the values for each of the four venues were added up to arrive at the value for the state smoking restriction variable. Local area restrictions were not included, as the dataset did not publicly identify respondents' residences within states.

To adjust for overall trends in state-level economic indicators, yearly state poverty rates were included as a continuous covariate. State median household income and state unemployment rate were considered as potential co- variates, but because of their high correlations with other variables, they were excluded from final analyses. The four state-level variables that had the strongest support in the literature and the data available for inclusion remained: state cigarette price, state beer price, the magnitude of state smoke-free laws, and state poverty rate.

\section{Other variables}

Year and state dummy variables were included as fixed effects to account for other unmeasured factors at the state level that might have been correlated with smoking and drinking. The survey year (dichotomous as either 2001, 2002, 2003, 2004, 2005, 2006, or not) and state of residence (one out of a possible 47 possible states and the District of Columbia) were included as dichotomous variables. Finally, we weighted all data using the BRFSS weights. These weights adjust for non-response and non-coverage for geographical strata, to adhere to sample estimates of those geographical areas, and to take into account state stratification by age, gender, and race/ethnicity. Full details of the BRFSS design and weighting are available elsewhere [43].

\section{Statistical analyses}

To test study hypotheses and address clustering that may occur at the state level over time, we estimated a series of linear regression equations using state and year as fixed effects [56]. A concern when conducting state policy research is that there could be confounding from unobserved characteristics of the state that are correlated with both smoking and cigarette price (e.g. anti-smoking sentiment). The benefit of using state effects, e.g. fixed effects, is that they account for any such unmeasured state-level characteristics that remain constant over time and may influence outcomes.

Univariate and bivariate analyses were conducted to determine variable means and relationships between cigarette price, age and smoking, and similarly for the three drinking variables. For each of the four outcome variables we estimated a linear probability model (LPM), using interaction terms (which interacted each age group with mean state cigarette price) to test hypotheses. All models included the same variables. Although the outcomes were binary, for which logistic regression usually is used, our inclusion of interaction terms introduces challenges with interpretation in nonlinear models. LPM has been found to be an appropriate and useful method for interpreting interaction terms when estimating models for binary outcomes [13,14,5659]. The coefficients from each of four regression models were then used to derive the predicted response, separately by age group, of each behavior to a $\$ 1$ increase in cigarette price, and expressed as percentage point changes.

All statistical analyses were performed using SAS version 9.2 (SAS Institute, Cary, North Carolina), utilizing procedures that address the complex sampling design of 
the BRFSS and adjust standard errors using the Taylor linearization method for computing variances [60]. The LPM models were estimated using OLS for weighted survey data (SAS PROC SURVEYREG). SAS options specified that models predicted the probability of smoking and drinking rather than the probability of not smoking or not drinking. The study was deemed exempt by the Brandeis University Committee for the Protection of Human Subjects.

\section{Results}

Table 1 provides weighted descriptions of the sample, including cigarette pack price, socio-demographics and state-level policy variables. The six-year mean of the main independent variable, state cigarette price per pack, adjusted for inflation, was $\$ 2.02$ (range, \$1.95-2.09). Of importance for this study, $4.32 \%$ of the sample was aged $18-20,16.49 \%$ aged $21-29,64.27 \%$ aged $30-64$, and $14.92 \%$ aged 65 and older. The analytic sample is slightly older compared to U.S. Census Data from 2002 [61].

Table 2 shows how the weighted prevalences of smoking and drinking behaviors vary by age group. Overall smoking prevalence was $21.79 \%$, drinking $55.38 \%$, binge drinking $15.69 \%$, and heavy drinking $5.43 \%$. These overall prevalence rates mask statistically significant $(\mathrm{p}<.001)$ differences by age group for each outcome. Those aged 65 and older have lower prevalence rates of smoking, and current, binge, and heavy drinking than those younger than 65 years of age. Those aged 18-20 have higher prevalence rates of all four behaviors than adults aged 65 and older. Additionally, adults aged 21-29 have the highest prevalence rates of smoking and all three drinking patterns.

Regression results in Table 3 suggest that age group influences the associations between state cigarette price, smoking, and patterns of drinking. The cigarette price coefficient from the LPM results predicts the change in the probability of current smoking; and current, binge, and heavy drinking among the reference group (those aged 65 and older) from a one-dollar increase in the mean state cigarette price [56]. The coefficients on the interaction terms capture the differences from the reference group in the response of smoking and drinking behaviors to the state cigarette price. For example, the coefficient on "cigarette price $\mathrm{x}$ aged 21-29" (the interaction term) for binge drinking is 0.060 . This indicates that the response of binge drinking to a one dollar increase in cigarette price is 6.00 percentage points higher for those aged 21-29 than it is for those aged 65 and older. Furthermore, the positive coefficients in Table 3 indicate that an increase in state cigarette price is associated with increases in the probability of smoking/drinking, while negative coefficients indicate associations with decreases in the probability of those behaviors. For example, for those aged 30-64, the negative coefficients on the interaction terms indicate that an increase in state cigarette price is associated with a reduction in the probability of current smoking and current drinking, compared to the reference group. However, the positive coefficient indicates that an increase in state cigarette price is associated with an increase in binge drinking among this population, compared to the reference group. Nearly all the coefficients on the interaction terms (e.g. cigarette price $x$ aged 18-20) are statistically significant, indicating differences (both increases and decreases) from the reference age group (those 65 and older) in the response of smoking and drinking patterns to the state price of cigarettes.

Table 4 presents predicted responses by age group to a $\$ 1$ increase in state cigarette price, based on the models estimated in Table 3. The results are expressed as predicted percentage point changes [56]. An increase in cigarette price was not associated with a significant change in smoking for those aged 18-29. However, a \$1 increase in cigarette price was associated with a significant decrease in smoking of 1.10 percentage points among those aged 30-64, and an increase in smoking of 1.43 percentage points among those aged 65 and older.

Cigarette price was associated with current, binge, and heavy drinking differentially by age group. For current drinking, a $\$ 1$ increase in cigarette price was associated with an increase in drinking prevalence of 3.72 percentage points for those aged 65 and older, and a reduction of 4.02 percentage points for those aged 18-20. A $\$ 1$ increase in price was associated with an increase in binge drinking of 4.06 percentage points for those aged 21-29, and a reduction of 1.95 percentage points for those aged 65 and older. Finally, an increase in cigarette price was associated with a significant increase of 1.15 percentage points in heavy drinking for those aged 21-29, a population that already has higher rates of drinking. An increase in cigarette price did not significantly impact any drinking pattern for those adults 30-64.

\section{Discussion}

This study examined the associations of state cigarette prices with smoking, and current, binge, and heavy drinking by age group. The study's novel findings are that increases in cigarette price are associated with increased smoking and drinking among those 65 and older, and increased binge and heavy drinking among those aged 21-29. These associations were not necessarily in the directions initially hypothesized. As shown in Table 3, the hypothesis that increases in state cigarette prices would produce stronger reductions in smoking and stronger increases in current, binge, and heavy drinking among young adults (those under 30 years of age), than among those aged 30-64 and 65 and older did not always hold. 
Table 1 Sample descriptive statistics among adults aged 18+,BRFSS, 2001-2006 ${ }^{\text {(a) }}$

\begin{tabular}{|c|c|}
\hline Variable & $\%$ or mean $(\mathrm{SE})$ \\
\hline \multicolumn{2}{|l|}{$N=1,323,758$} \\
\hline \multicolumn{2}{|c|}{ Cigarette price, $\$$ per pack ${ }^{(b)}$, by year and 6 year means } \\
\hline 2001 & $\$ 1.95(0.00)$ \\
\hline 2002 & $2.09(0.00)$ \\
\hline 2003 & $2.06(0.00)$ \\
\hline 2004 & $2.01(0.00)$ \\
\hline 2005 & $2.03(0.00)$ \\
\hline 2006 & $1.98(0.00)$ \\
\hline 6-year mean & $\$ 2.02(0.00)$ \\
\hline Female gender, \% & 50.54 \\
\hline \multicolumn{2}{|l|}{ Age group,\% } \\
\hline $18-20$ & 4.32 \\
\hline $21-29$ & 16.49 \\
\hline $30-64$ & 64.27 \\
\hline 65 and higher & 14.92 \\
\hline \multicolumn{2}{|l|}{ Poverty, \% } \\
\hline Not poor & 84.89 \\
\hline Poor & 8.91 \\
\hline Maybe poor ${ }^{(c)}$ & 6.19 \\
\hline \multicolumn{2}{|l|}{ Race/ethnicity, \% } \\
\hline Non-Hispanic White & 71.14 \\
\hline $\begin{array}{l}\text { Non-Hispanic } \\
\text { African American }\end{array}$ & 9.62 \\
\hline Non-Hispanic Asian & 2.63 \\
\hline $\begin{array}{l}\text { Non-Hispanic Native } \\
\text { Hawaiian Pacific Islander }\end{array}$ & 0.36 \\
\hline $\begin{array}{l}\text { Non-Hispanic } \\
\text { American Indian } \\
\text { Alaskan Native }\end{array}$ & 1.08 \\
\hline Non-Hispanic other race ${ }^{(d)}$ & 0.78 \\
\hline Non-Hispanic multi-race & 1.51 \\
\hline Hispanic & 12.88 \\
\hline Have partner, \% & 64.10 \\
\hline \multicolumn{2}{|l|}{ Employment status, \% } \\
\hline Unemployed & 5.05 \\
\hline Employed & 64.64 \\
\hline Out of workforce & 30.35 \\
\hline \multicolumn{2}{|l|}{ Educational level, \% } \\
\hline$<$ High school degree & 11.14 \\
\hline High school grad & 29.45 \\
\hline Some college & 27.28 \\
\hline College graduate or more & 32.12 \\
\hline \multicolumn{2}{|l|}{ State-level co-variates } \\
\hline Beer price, \$ per six-pack ${ }^{(b)}$ & $\$ 3.99(0.00)$ \\
\hline
\end{tabular}

Table 1 Sample descriptive statistics among adults aged 18+,BRFSS, 2001-2006 ${ }^{\text {(a) }}$ (Continued)

\author{
Magnitude of state smoke-free \\ $4.17(0.00)$ \\ laws (range 0-12), mean \\ State poverty rate, mean \\ $0.12(0.00)$ \\ Notes: BRFSS = Behavioral Risk Factor Surveillance System Surveys. \\ $\mathrm{SE}=$ Standard error \\ (a) Weighted data are presented to reflect the complex sampling design of \\ Behavioral Risk Factor Surveillance System (BRFSS). \\ (b) In 1982-4 dollars, adjusted for inflation. \\ (c) BRFSS income response categories do not track exactly with poverty \\ guidelines limits, responses that were impossible to discern whether in \\ poverty or not were coded as "maybe poor". \\ (d) "Non-Hispanic other race" is not further defined in the BRFSS code book.
}

In terms of current smoking, the response for those aged 30-64 mirrored the bulk of the literature: an increase in cigarette price was associated with a decrease in smoking $[10,11]$. However, as indicated in Table 4, smoking among the age groups under 30 was not associated with a significant response to cigarette price in this study. This finding is similar to Sloan and Trogdon, who also did not detect significant associations in a study including those aged 21-24 [62]. While a longitudinal study by Tauras, et al. concluded that increases in cigarette price reduced smoking prevalence among youth and young adults, the respondents in that sample were aged 12-22 [49]. Those younger age groups may have responded differently than the categories of 18-29 year olds used in this study. The finding that those aged 65 and older increased smoking prevalence at higher cigarette prices was unexpected, though cigarette price studies of this specific age group are rare $[38,63]$.

For current drinking, and consistent with some other studies $[14,64]$, this study found that higher state cigarette prices were associated with significantly lower rates of current drinking among those aged 18-20, who are not able to purchase alcohol legally for their general consumption. For those aged 65 and older, an increase in cigarette price was associated with a significant increase in rates of current drinking. Another study also found increases in cigarette price associated with increased drinking consumption in older adults [38]. It is possible that increases in cigarette price may be the final motivation for those aged 65 and older to stop smoking, and they may potentially substitute a drink for their smoking. For this age group, which is often on limited budgets, a drink now and then may be less expensive than maintaining smoking [65]. Although this age group has lower overall rates of use, even current drinking may be unhealthy, as its members are more likely than younger age groups to suffer from multiple chronic health conditions, and experience interactions with medications that may be further complicated by drinking. This is a particularly important consideration as the U.S. faces a growing aging population. The response of current drinking to changes in cigarette price 
Table 2 Smoking and drinking prevalence rates by age group, BRFSS, 2001-6 ${ }^{\text {(a) }}$

\begin{tabular}{|c|c|c|c|c|c|c|c|c|}
\hline Variable & $\begin{array}{l}\text { Current } \\
\text { smoking }\end{array}$ & SE & $\begin{array}{l}\text { Current } \\
\text { drinking }\end{array}$ & SE & $\begin{array}{l}\text { Binge } \\
\text { drinking }^{(c)}\end{array}$ & SE & $\begin{array}{l}\text { Heavy } \\
\text { drinking }\end{array}$ & SE \\
\hline \multicolumn{9}{|c|}{$\mathrm{N}=1,323,758^{(\mathrm{b})}$} \\
\hline Total & 21.79 & 0.00 & 55.38 & 0.00 & 15.69 & 0.00 & 5.43 & 0.00 \\
\hline \multicolumn{9}{|c|}{ Age group $^{(\mathrm{d}) * * *}$} \\
\hline $18-20$ & 24.19 & 0.49 & 47.05 & 0.58 & 25.26 & 0.55 & 8.40 & 0.35 \\
\hline $21-29$ & 27.58 & 0.22 & 63.95 & 0.24 & 28.99 & 0.25 & 8.44 & 0.15 \\
\hline $30-64$ & 22.92 & 0.08 & 56.99 & 0.10 & 14.48 & 0.08 & 4.97 & 0.04 \\
\hline $\begin{array}{l}65 \text { and } \\
\text { older }\end{array}$ & 9.84 & 0.11 & 41.40 & 0.18 & 3.45 & 0.08 & 3.23 & 0.07 \\
\hline
\end{tabular}

Notes: BRFSS = Behavioral Risk Factor Surveillance System Surveys.

$\mathrm{SE}=$ standard error.

(a) Weighted unadjusted percents are presented to reflect the complex sampling design of Behavioral Risk Factor Surveillance System (BRFSS) 20012006.

(b) $\mathrm{N}=1,323,758$. This is the sample used for all analyses, except as noted. (c) $\mathrm{N}=1,050,573$. Includes observations for 2001-2005 only due to change in definition of binge drinking in 2006.

(d) Data represent chi-square statistics.

*** Age group has a statistically significant association with all four column variables (Overall chi-square $\mathrm{df}=3, \mathrm{p}<.001$, for each column variable).

of those aged 21-64 was not significantly different from zero.

A concerning finding from this study is that higher cigarette prices were associated with higher rates of both binge and heavy drinking among those aged 21-29, the age group that already has the highest prevalence of smoking and current, binge and heavy drinking of any age group. The response of binge and heavy drinking to cigarette price did not vary across the other age groups, with the exception of a reduction in binge drinking for those aged 65 and older. Only one other study, by Dee [14], compared different forms of drinking outcomes to increases in cigarette taxes among teens. While his models with fewer co-variates found a complementary relationship between cigarette tax and heavy drinking among teens (i.e. as tax increases, drinking decreases), in the more complex models adjusting for state and year effects, Dee also did not find a significant association between cigarette tax and heavy drinking among teens. In the present study, an increase in cigarette price was associated with an increase in current drinking for those aged 65 and older, perhaps due to substituting drinking for smoking. However, it is plausible that smokers in this age group who were binge drinkers might have a different response to increases in cigarette price. It is possible when cigarette prices increased, smokers who both smoked and binge-drank quit both behaviors, but this would not have been detectable in pseudo-panel data. In order to discern these relationships further, longitudinal studies that track the same individuals over time are needed.

Previous studies have found that drinking increases in response to increases in cigarette price [13,18,38], but those

Table 3 Parameter estimates: smoking and drinking response to cigarette price by age group, BRFSS, 2001-6 ${ }^{(a)}$

\begin{tabular}{|c|c|c|c|c|}
\hline Independent variables & Current Smoking $\beta$ (SE) & Current Drinking $\beta$ (SE) & Binge Drinking ${ }^{(c)} \beta$ (SE) & Heavy Drinking $\beta$ (SE) \\
\hline \multicolumn{5}{|l|}{$\mathrm{N}=1,323,758^{(\mathrm{b})}$} \\
\hline State cigarette pack price (\$) & $0.014^{*}(0.007)$ & $0.037^{* * *}(0.009)$ & $-0.019 * *(0.007)$ & $0.001(0.004)$ \\
\hline \multicolumn{5}{|l|}{ Age (reference $=65$ and older } \\
\hline $18-20$ & $0.128^{* * *}(0.029)$ & $0.215^{* * *}(0.034)$ & $0.060(0.032)$ & $0.027(0.019)$ \\
\hline $21-29$ & $0.195^{* * *}(0.014)$ & $0.264^{* * *}(0.016)$ & $0.104^{* * *}(0.014)$ & $0.027^{* *}(0.009)$ \\
\hline $30-64$ & $0.211^{* * *}(0.008)$ & $0.140^{* * *}(0.011)$ & $0.054^{* * *}(0.006)$ & $0.023^{* * *}(0.004)$ \\
\hline Cigarette price $x$ aged $18-20$ & $-0.032^{*}(0.014)$ & $-0.077^{* * *}(0.017)$ & $0.049 * *(0.016)$ & $0.005(0.010)$ \\
\hline Cigarette price $\times$ aged 21-29 & $-0.006(0.007)$ & $-0.045^{* * *}(0.008)$ & $0.060^{* * *}(0.007)$ & $0.011 *(0.004)$ \\
\hline Cigarette price $x$ aged 30-64 & $-0.025^{* * *}(0.004)$ & $-0.029^{* * *}(0.005)$ & $0.019^{* * *}(0.003)$ & $-0.002(0.002)$ \\
\hline \multicolumn{5}{|l|}{ Year $(\text { reference }=2006)^{(d)}$} \\
\hline 2001 & $0.025^{* * *}(0.003)$ & $0.022^{* * *}(0.004)$ & $0.002(0.003)$ & $0.002(0.002)$ \\
\hline 2002 & $0.022^{* * * *}(0.003)$ & $0.030^{* * *}(0.004)$ & $0.013^{* * *}(0.003)$ & $0.007^{* * *}(0.002)$ \\
\hline 2003 & $0.021^{* * *}(0.003)$ & $0.043^{* * *}(0.003)$ & $0.016^{* * *}(0.002)$ & $0.007^{* * *}(0.002)$ \\
\hline 2004 & $0.008^{* *}(0.003)$ & $0.028^{* * *}(0.003)$ & $0.005^{*}(0.002)$ & $0.002(0.002)$ \\
\hline 2005 & $0.006^{* *}(0.002)$ & $0.015^{* * *}(0.003)$ & 0 & $0.002(0.001)$ \\
\hline
\end{tabular}

Notes: Models included covariates for gender, poverty status, race/ethnicity, co-habitating partner status, employment status, educational level, beer price (six-pack), magnitude of state smokefree laws, state poverty rate.

$\beta=$ beta for parameter estimate; $\mathrm{SE}=$ Standard Error; ${ }^{*} \mathrm{p}<.05,{ }^{* *} \mathrm{p}<.01,{ }^{* * *} \mathrm{p}<.001$, using t-tests, df $=1,320,358$ for current smoking, current drinking, and heavy drinking, $\mathrm{df}=1,047,879$ for binge drinking.

(a) Weighted data are presented to reflect the complex sampling design of Behavioral Risk Factor Surveillance System (BRFSS).

(b) $\mathrm{N}=1,323,758$. This is sample used for all analyses, except as noted.

(c) $\mathrm{N}=1,050,573$. Dropped all observations from 2006 in binge drinking analyses to reflect change in definition of binge drinking for women in that year.

(d) Reference year is 2006 for all analyses except binge drinking analysis, when reference year is 2005. 
Table 4 Predicted smoking and drinking response to cigarette price-by age group, BRFSS 2001-6 ${ }^{\text {(a) }}$

\begin{tabular}{|c|c|c|c|c|}
\hline & $\begin{array}{l}\text { Current } \\
\text { Smoking }\end{array}$ & $\begin{array}{l}\text { Current } \\
\text { Drinking }\end{array}$ & $\begin{array}{l}\text { Binge } \\
\text { Drinking }\end{array}$ & $\begin{array}{l}\text { Heavy } \\
\text { Drinking }\end{array}$ \\
\hline & $\begin{array}{l}\text { Percentage } \\
\text { point change }\end{array}$ & $\begin{array}{l}\text { Percentage } \\
\text { c) point change }\end{array}$ & $\begin{array}{l}\text { Percentage } \\
\text { (c) point change }\end{array}$ & $\begin{array}{l}\text { Percentage } \\
\text { d) point change }\end{array}$ \\
\hline \multicolumn{5}{|c|}{$N=1,323,758^{(b)}$} \\
\hline \multicolumn{5}{|c|}{ Age group } \\
\hline $18-20$ & -1.76 & $-4.02^{*}$ & 2.98 & 0.56 \\
\hline $21-29$ & 0.83 & -0.83 & $4.06^{* * *}$ & $1.15^{* *}$ \\
\hline $30-64$ & $-1.10^{* *}$ & 0.82 & -0.09 & -0.19 \\
\hline $\begin{array}{l}65 \text { and } \\
\text { older }\end{array}$ & $1.43^{*}$ & $3.72^{* * *}$ & $-1.95^{* *}$ & 0.05 \\
\hline
\end{tabular}

Notes: Models included covariates for gender, poverty status, race/ethnicity, co-habitating partner status, employment status, educational level, beer price (six-pack), magnitude of state smokefree laws, state poverty rate. BRFSS = Behavioral Risk Factor Surveillance System Surveys.

${ }^{*} \mathrm{p}<.05$, ** $\mathrm{p} \leq .01,{ }^{* * *} \mathrm{p}<.001$, using t-tests, $\mathrm{df}=1,320,358$, for current smoking current drinking, and heavy drinking, $\mathrm{df}=1,047,879$ for binge drinking. (a) Weighted data are presented to reflect the complex sampling design of Behavioral Risk Factor Surveillance System (BRFSS) 2001-2006.

(b) This is sample used for all analyses, except as noted.

(c) Percentage point change reflects predicted changes in smoking and drinking pattern response to a $\$ 1$ increase in state cigarette price.

(d) $N=1,050,573$. Includes observations for 2001-2005 only due to change in definition of binge drinking in 2006.

studies did not compare responses across age groups. The findings about associations with increased binge and heavy drinking among adults aged 21-29 underscore the importance of examining different patterns of drinking in response to cigarette price across age groups. Future research could: 1) investigate associations interacting age group with other demographic variables (e.g. gender, race/ethnicity) related to smoking and drinking outcomes, and 2) examine factors (e.g. biological, psychosocial, developmental, marketing) contributing to increased drinking behaviors among certain age groups in response to cigarette price. Such research could provide insight for effective interventions with specific populations.

This study has limitations and strengths. First, BRFSS does not collect data on persons who live in institutions, the military, and the homeless. Second, as a telephone survey, the dataset may have bias due to its under-coverage of those individuals who do not have landlines. BRFSS documentation acknowledges that some populations (e.g. those in the rural areas, African Americans in the South, low income populations, and young adults) are less likely to have landlines and the data may not be representative of those populations [66]. However, the weighting adjustments made using the BRFSS weights minimized the impact of such non- or under-coverage [66]. Third, the BRFSS does not track the same individuals over time, nor does it include variables relating to the level of nicotine and alcohol addiction. Thus, it was not possible to analyze differences in demand response due to addiction, or to an individual's behavior over time. Fourth, in the years of this study, the BRFSS does not include variables that address the number of cigarettes smoked. This information could have provided more understanding on whether individuals reduce the number of cigarettes smoked (rather than quitting) in response to increases in cigarette price. Fifth, the BRFSS relies on self-report for smoking and drinking. While the amount consumed may be underreported, whether someone participates in smoking and/or drinking may be less prone to misreporting [52]. To the extent that underreporting of amount of alcohol consumed occurred, binge and heavy drinking results may be underestimated. While lacking in some areas, the BRFSS was the only dataset that provided publicly available state identifiers, demographics, and information on the health behaviors critical to this study. Sixth, the beer price variable was based on the price of Heineken, which is commonly used in the literature [52], but may introduce potential measurement bias. Finally, while using state fixed effects addresses bias from state characteristics that do not change over time, it does not address all bias, including uncontrolled variables that change over time. Nonetheless, strengths of this study were the controls for state and year fixed effects, the magnitude of smoke-free laws in a state, and state poverty rates. Much of the recent literature stresses the importance of accounting for these factors, which previous studies may have omitted $[67,68]$.

\section{Conclusions}

In summary, age matters, as cigarette prices can be associated with unintended consequences on smoking and drinking behaviors among and across different age groups. Understanding the effects of cigarette taxation policy on different populations is important, as there has been a trend over the last decade for states to increase cigarette taxes, both to advance public health goals, as well as to fill dwindling state coffers. This study adds some cautionary information to decision-makers regarding the attainment of public health goals. Although increasing cigarette taxes has been used widely to prevent and reduce tobacco use, this study suggests there may be unintended consequences for policymakers to consider. Increases in cigarette taxes may result in reductions in: smoking among those aged 30-64, drinking among those aged 18-20, and binge drinking among those aged 65 and older. However, increases in cigarette price through taxation could increase: smoking and drinking among those 65 and older, and binge and heavy drinking among those aged 21-29. Preparing for potential increases in problematic drinking among these age groups could be considered through targeted programming to populations and outreach to practitioners.

Additionally, while there are many researchers and advocates in the alcohol prevention and tobacco control fields, few study both topics. More interdisciplinary 
behavioral, economic, and health research would benefit our understanding of the prevention, use and co-use of alcohol and nicotine. Advocates and policy-makers could also collaborate and coordinate on policy-making after research has been conducted and plans made for unintended consequences. To our knowledge, a national, purposive, simultaneous campaign to increase alcohol and tobacco prices together has not been conducted, and it is unclear whether such efforts have occurred on the state level. Before creating a campaign to increase simultaneously taxes on alcohol and tobacco products, economic modeling is needed both to arrive at an optimal tax and to understand potential unintended consequences, like the ones found in this study. Tobacco control and alcohol prevention researchers, advocates, practitioners, and policymakers should work together to understand and prepare for unintended consequences of tobacco taxation policy.

\section{Abbreviations}

BRFSS: Behavioral risk factor surveillance system survey; LPM: Linear probability model; SE: Standard error.

\section{Competing interests}

The authors declare that they have no competing interests.

\section{Authors' contributions}

DM conceptualized the study, conducted the analyses, interpreted data, and drafted the article. DH advised on study design and analyses. DH, PF, SR, and $\mathrm{CH}$ contributed to interpretation and manuscript revisions. All authors read and approved the final manuscript.

\section{Acknowledgments}

The authors would like to acknowledge Grant Ritter for statistical advice; John Tauras for advice on study design and variables, and interpretation of data; and Gregory Bloss for advice on alcohol measures and modeling. The research was supported by award numbers T32AA007567 and F31AA018587 from the National Institute on Alcohol Abuse and Alcoholism (NIAAA). The content is solely the authors' responsibility and does not necessarily represent the official views of the NIAAA, its staff, or the National Institutes of Health.

\section{Author details}

${ }^{1}$ Institute for Behavioral Health, Heller School for Social Policy and Management, Brandeis University, 415 South Street, MS035, Waltham, MA 02454-9110, USA. ${ }^{2}$ Cancer Prevention and Control, University of Hawaii Cancer Center, 677 Ala Moana Blvd. Gold Bond Building, Suite 200, Honolulu, HI 96813, USA.

Received: 24 February 2012 Accepted: 28 June 2012

Published: 11 July 2012

\section{References}

1. Babor T, Caetano R, Casswell S, Edwards G, Giesbrecht N, Graham K, Gruenewald P, Hill L, Holder H, Homel R, et al: Alcohol: No ordinary commodity. Research and public policy. New York: Oxford University Press; 2003.

2. Institute of Medicine: Ending the tobacco problem: A blueprint for the nation. Washington, DC: National Academies Press; 2007.

3. Centers for Disease Control and Prevention: Alcohol-attributable deaths report, average for United States. http://apps.nccd.cdc.gov/ardi.

4. Centers for Disease Control and Prevention: Smoking-attributable mortality, years of potential life lost, and productivity losses - United States, 2000-2004. MMWR Morb Mortal Wkly Rep 2008, 57:1226-1228.

5. Centers for Disease Control and Prevention: Annual smoking-attributable mortality, years of potential life lost, and economic costs - United States, 1995-1999. MMWR Morb Mortal Wkly Rep 2002, 51:300-302.
6. Institute of Medicine: Improving the quality of health care for mental and substance-use conditions. Washington, DC: The National Academies Press; 2006.

7. Coate D, Grossman M: Effects of alcohol prices and legal drinking ages on youth alcohol use. J Law Econ 1988, 31:145-171.

8. Cook PJ, Tauchen G: The effect of liquor taxes on heavy drinking. Bell J Econ 1982, 13:379-390.

9. Lewit EM, Coate D, Grossman M: The effects of government regulation on teenage smoking. J Law Econ 1981, 24:545-569.

10. Warner KE: Tobacco policy research: Insights and contributions to public health policy. San Francisco, CA: Jossey-Bass; 2006.

11. Chaloupka FJ, Warner K: The economics of smoking. In Handbook of health economics, Volume 1. Edited by Culyer A, Newhouse J. NY: Elsevier Science; 2000:1541-1626

12. Cook PJ, Moore MJ: The economics of alcohol abuse and alcohol-control policies. Health Aff 2002, 21:120-133.

13. Decker SL, Schwartz AE: Cigarettes and alcohol: Substitutes or complements. In NBER Working Paper Series. Edited by National Bureau of Economic Research. Cambridge, MA: National Bureau of Economic Research; 2000.

14. Dee TS: The complementarity of teen smoking and drinking. J Health Econ 1999, 18:769-793

15. Falk DE, Yi HY, Hiller-Sturmhofel S: An epidemiologic analysis of cooccurring alcohol and tobacco use and disorders. Alcohol Res Health 2006, 29:162-171.

16. Goel RK, Morey MJ: The interdependence of cigarette and liquor demand. South Econ J 1995, 62:451-459.

17. Jones AM: A systems approach to the demand for alcohol and tobacco. Bull Econ Res 1989, 41:85-105.

18. Markowitz S, Tauras JA: Substance use among adolescent students with consideration of budget constraints. Rev Econ Househ 2009, 7:423-446.

19. Pindyck RS, Rubinfeld DL: Microeconomics 4th edn. Upper Saddle River, NJ: Prentice Hall; 1998.

20. Davis TJ, de Fiebre CM: Alcohol's actions on neuronal nicotinic acetylcholine receptors. Alcohol Res Health 2006, 29:179-185.

21. Funk D, Marinelli PW, Le AD: Biological processes underlying co-use of alcohol and nicotine: neuronal mechanisms, cross tolerance, and genetic factors. Alcohol Res Health 2006, 29:186-192.

22. Grucza RA, Bierut LJ: Co-occurring risk factors for alcohol dependence and habitual smoking. Alcohol Res Health 2006, 29:172-178.

23. Madden PA, Bucholz KK, Martin NG, Heath AC: Smoking and the genetic contribution to alcohol-dependence risk. Alcohol Res Health 2000, 24:209-214.

24. Little HJ: Behavioral mechanisms underlying the link between smoking and drinking. Alcohol Res Health 2000, 23:215-224.

25. Centers for Disease Control and Prevention: Cigarette smoking among adults-United States, 2007. MMWR Wkly 2008, 57:1221-1226.

26. Substance Abuse, Mental Health Services Administration: Results from the 2006 National Survey on Drug Use and Health: National finding. Rockville, MD: U.S. Department of Health and Human Services, Substance Abuse and Mental Health Services Administration, Office of Applied Studies; 2007.

27. Lucas JW, Schiller JS, Benson V: Summary health statistics for U.S. adults: National Health Interview Survey, 2001. In Vital statistics. Washington, DC: National Center for Health Statistics; 2004.

28. Blazer DG, Wu LT: Patterns of tobacco use and tobacco-related psychiatric morbidity and substance abuse among middle-aged and older adults in the U.S. Aging Ment Health 2012, 16:296-304.

29. Lee MR, Chassin L, Mackinnon D: The effect of marriage on young adult heavy drinking and its mediators: Results from two methods of adjusting for selection into marriage. Psychol Addict Beh 2010 Dec, 24:712-718.

30. Waldron M, Heath A, Lynsky M, Bucholz K, Madden P, Martin N: Alcoholic marriage: later start, sooner end. Alcohol Clin Exp Res 2011 April, 35:632-642

31. Garrett B, Dube S, Trosclair A, Caraballo R, Pechacek T: Cigarette Smoking — United States, 1965-2008. MMWR 2011, 60:109-113.

32. National Cancer Institute: The role of media in promoting and reducing tobacco use. Bethesda, MD: U.S. Department of Health and Human Services, National Institutes of Health, National Cancer Institute. NIH Pub. No. 07-6242; 2008

33. Saffer $\mathrm{H}$ : Alcohol advertising and alcohol consumption by adolescents. Heal Econ 2006, 15:617-637.

34. Bobo JK, Husten C: Sociocultural influences on smoking and drinking. Alcohol Res Health 2000, 24:225-232.

35. Gruenewald PJ, Ponicki WR, Holder HD: The relationship of outlet densities to alcohol consumption: a time series cross-sectional analysis. Alcohol Clin Exp Res 1993, 17:38-47. 
36. Adams S, Cotti C: Drunk driving after the passage of smoking bans in bars. J Public Econ 2008, 92:1288-1305.

37. Pindyck Robert S, Rubinfeld Daniel L: Microeconomics. Fourthth edition. Upper Saddle River, NJ: Prentice Hall; 1998.

38. Picone G, Sloan F, Trogdon J: The effect of the tobacco settlement and smoking bans on alcohol consumption. Health Econ 2004, 13:1063-1080.

39. Bask M, Melkersson M: Rationally addicted to drinking and smoking? App Econ 2004, 36:373-381

40. Cameron L, Williams J: Cannabis, alcohol, and cigarettes: substitutes or complements? Econ Rec 2001, 77:19-34.

41. Substance Abuse, Mental Health Services Administration: Results from the 2005 National Survey on Drug Use and Health: National Findings. Rockville, MD: SAMHSA Office of Applied Studies; 2006.

42. Centers for Disease Control and Prevention: Vital signs: current cigarette smoking among adults aged $\geq 18$ years -- United States, 2005-2010. MMWR Wkly 2011, 60:1207-1212.

43. BRFSS Annual Survey Data. http://www.cdc.gov/brfss/technical_infodata/ surveydata.htm.

44. Allison PD: Missing data. Thousand Oaks, CA: Sage Publications; 2002

45. Centers for Disease Control and Prevention: Behavioral risk factor surveillance system survey data. Atlanta, GA: U.S. Department of Health and Human Services, Centers for Disease Control and Prevention; 2006.

46. Orzechowski and Walker: The tax burden on tobacco, historical compilation Vol 42. Arlington, VA: Orzechowski and Walker; 2007.

47. Tauras J: Smoke-free air laws, cigarette prices, and adult cigarette demand. Econ Inq 2006, 44:333-342.

48. U.S. Department of Labor, Bureau of Labor Statistics: Consumer price index. $\mathrm{ftp}: / / \mathrm{ftp} . \mathrm{bls} . g o v / p u b / s p e c i a l . r e q u e s t s / c p i / c p i a i . t x t$

49. Tauras J, Markowitz S, Cawley J: Tobacco control policies and youth smoking: Evidence from a new era. In Substance use: Individual behavior, social interactions, markets and politics Advances in health economics and health services research, Volume 16. Edited by Lindgren J. New York: Elsevier; 2005:277-291.

50. U.S. Department of Health and Human Services: Prior HHS Poverty Guidelines and Federal Register References. http://aspe.hhs.gov/POVERTY/ figures-fed-reg.shtml.

51. American Chamber of Commerce Researchers Association: Inter-city cost of living index. In Inter-city cost of living index. Edited by American Chamber of Commerce Researchers Association. Arlington, VA: American Chamber of Commerce Researchers Association; 2001-2006.

52. Cook PJ, Moore MJ: Alcohol. In Handbook of health economics, Volume 1. Edited by Culyar AJ, Newhouse JP. NY: Elsevier Science; 2000:1630-1672.

53. Ross H, Chaloupka FJ: The effect of public policies and prices on youth smoking. South Econ J 2004, 70:796-815.

54. Centers for Disease Control and Prevention: State smoke-free indoor air fact sheet. http://apps.nccd.cdc.gov/statesystem/publications/ STATEsystemfactsheetsmokefree.pdf.

55. Tynan M, Babb S, MacNeil A: State smoking restrictions for private-sector worksites, restaurants, and bars - United States, 2004 and 2007. MMWR Morb Mortal Wkly Rep 2008, 57:549-552.

56. Wooldridge J: Introductory econometrics. 3rd edition. USA: Thomson SouthWestern; 2006

57. Ai C, Norton E: Interaction terms in logit and probit models. Econ Lett 2003, 80:123-129.

58. Domino M, Norton E, Morrissey J, Thakur N: Cost shifting to jails after a change to managed mental health care. Health Serv Res 2004, 39:1379-1402.

59. Liu Z, Dow W, Norton E: Effect of drive-through delivery laws on postpartum length of stay and hospital charges. J Health Econ 2004, 23:129-155.

60. SAS Institute Inc: The SURVEYREG procedure, SAS/STAT ${ }^{\circledR} 92$ User's Guide. Cary, NC: SAS Institute Inc; 2008.

61. U.S. Census Bureau: Table 1. Population by Age, Sex, Race and Hispanic Origin: March 2002 Detailed-Tables (PPL-167). http://www.census.gov/ population/age/data/files/2002/table1.pdf.

62. Sloan F, Trogdon J: The impact of the master settlement agreement on cigarette consumption. J Policy Anal Manag 2004, 23:843-855.

63. DeCicca P, McLeod L: Cigarette taxes and older adult smoking: evidence from recent large tax increases. J Health Econ 2008, 27:918-929.

64. Goodman AC: Economic analysis of multiple addictions for men and women. J Ment Health Policy Econ 2009, 12:139-156.

65. Merrick EL, Horgan CM, Hodgkin D, Garnick DW, Houghton SF, Panas L, Saitz R, Blow FC: Unhealthy drinking patterns in older adults: prevalence and associated characteristics. J Am Geriatr Soc 2008, 56:214-223.
66. Comparability of data: BRFSS 2006. http://www.cdc.gov/brfss/ technical_infodata/surveydata/2006.htm.

67. Carpenter C, Cook PJ: Cigarette taxes and youth smoking: new evidence from national, state, and local Youth Risk Behavior Surveys. J Health Econ 2008, 27:287-299.

68. Tauras JA: Differential impact of state tobacco control policies among race and ethnic groups. Addiction 2007, 102(Suppl 2):95-103.

doi:10.1186/1747-597X-7-28

Cite this article as: McLellan et al:: Unintended consequences of cigarette price changes for alcohol drinking behaviors across age groups: evidence from pooled cross sections. Substance Abuse Treatment, Prevention, and Policy 2012 7:28.

\section{Submit your next manuscript to BioMed Central and take full advantage of:}

- Convenient online submission

- Thorough peer review

- No space constraints or color figure charges

- Immediate publication on acceptance

- Inclusion in PubMed, CAS, Scopus and Google Scholar

- Research which is freely available for redistribution

Submit your manuscript at www.biomedcentral.com/submit
C) Biomed Central 